\title{
Kajian Aksiologi terhadap Teknik Cryonics sebagai Solusi Menuju Kehidupan Kedua
}

\author{
Kadek Dwi Hendratma Gunawan \\ Politeknik Ganesha Guru, Bali, Indonesia \\ e-mail: hendratma.gunawan@gmail.com
}

\begin{abstract}
Improving science and technology is done to eliminate human boundaries and achieve happiness. The death that leads to grief tries to overcome. The concept of immortality is finally born from cryonics techniques. Using the library research method analyzed that, the cryonics technique provides an opportunity to live again in the future, after the death of an incurable illness today. But this technique is contrary to the ethical and aesthetic aspects of Indonesia. The belief in God is shaken by its incompatibility with the potentialities of the cryonics technique. The shift in the meaning of death both scientifically and legally needs to be reexamined. A view of the axiological study of cryonics techniques needs to be studied in more depth, especially so as not to become a problem in the future.
\end{abstract}

Keywords: acsiology, cryonics, etics, estetics, immortality

\section{Pendahuluan}

Salah satu aktor super hero The Avengers Series yaitu Captain America, aktor animasi science fiction dari film Futurama yaitu Fry, dan tokoh film Austin Power Series, ketiganya merupakan contoh tokoh-tokoh yang terbangun dari pembekuan di masa lalu. Nama terakhir yang jelas-jelas telah dibangunkan menggunakan teknik cryogenicsdan entah secara sengaja atau tidak, aktor-aktor tersebut tidak akan memainkan perannya tanpa pemahaman sutradara tentang cryonics. Cryonics berbeda dengan cryogenics. Cryogenics merupakan cabang ilmu fisika yang mengkaji produksi dan dampak dari suatu materi dalam suhu yang sangat rendah Oxford, 2003). Tantangan pun telah diterima oleh para ilmuan melalui kemajuan ilmu pengetahuan dan teknologi yang semakin pesat menuju masa depan, dimana segala sesuatu yang fantasi telah dibentuk dalam aktualitas (Pandhi, 2015).

Revolusi teknologi pada dunia medis untuk keselamatan membawa harapan keberadaan untuk terhindar dari penyakit dan kematian (Lafontaine, 2009). Aplikasi teknik untuk mencegah kematian tersebut dinamakan cryonics pada suhu yang hampir mencapai 0 mutlak dengan menggunakan campuran zat anti beku yaitu cryoprotectantyang dimasukkan untuk menggantikan cairan tubuh, sehingga sistem metabolisme tetap terjaga (Best, 2008; Pandhi, 2015; Budiyanti, 2016; Thomson, 2016). Hal ini dimaksudkan untuk proses pembekuan sesaat setelah kematian dengan maksud untuk menghidupkannya kembali di masa depan. (Lohmeier et al., 2015). Pertanyaan yang muncul adalah mungkinkah tubuh yang telah dalam keadaan membeku dapat melanjutkan kehidupan kedua secara normal layaknya sistem pause dari sebuah lagu yang dimainkan? Apabila ini dapat diterapkan maka seluruh umat manusia dapat hidup abadi. Kontroversi pun muncul ketika teknik cryonics mulai diangkat sebagai suatu kajian sekitar tahun 1967.

Kontroversi dikaitkan dengan agama, norma, dan nilai sosial bagi orang yang memiliki keyakinan tentang kehidupan dan kematian. Kaum spiritual meyakini bahwa urusan hidup dan mati seseorang merupakan kehendak Tuhan dalam mengatur dimensi kehidupan tanpa intervensi khususnya oleh manusia. Beberapa menganggap bahwa proses pembekuan ini ketika mati untuk penghidupan kembali di masa depan sebagai bagian dari fiksi ilmiah dan aneh (Shaw, 2011). Sebaliknya, para penganut atheis mungkin menganggap bahwa cryonics merupakan jalan menuju keabadian (Barbaro, 2011). Disamping itu, orang-orang yang mempercayai cryonics memiliki keyakinan tentang perkembangan nano teknologi dalam mengatasi keberlanjutan hidup dan percaya bahwa kremasi sebagai proses yang irreversible (Moen, 2015). Terdapat beberapa pilihan untuk cryonics yaitu pembekuan tubuh seluruhnya ataupun hanya bagian otak (neuropreservation). 
Data menunjukkan bahwa di Arizona, Amerika Serikat terdapat yayasan yang disebut Alcor Life Extension (the world's leader in cryonics) dengan pertumbuhan signifikan pada anggota dan pasiennya sepanjang tahun hingga 28 Februari 2018 berjumlah 1.159 orang, associated member sebanyak 274, dan pasien sebanyak 156 (www.alcor.org). Artikel ini akan membahas kajian aksiologi tentang teknik cryonicsyang dikaitkan dengan nilai-nilai yang terkandung didalamnya secara teori, sosial, ekonomi, pengambilan keputusan, dan agama. Kajian aksiologi ini didasarkan pada etika, estetika, dan berbagai rasional yang muncul terhadap teknik cryonics.

\section{Metode}

Metode yang digunakan adalah metode studi kepustakaan (library research). Penelaahan terhadap buku-buku, literatur-literatur, dan artikel ilmiah dilakukan untuk memperkaya kajian tentang cryonics. Data sekunder dari berbagai hasil penelitian atau percobaan merupakan jenis data yang kemudian disintesis hingga menjadi kesatuan dalam memberikan informasi.

\section{Hasil dan Pembahasan}

\section{Sekilas Tentang Teknik Cryonics}

Teknik cryonics dapat dikatakan sebagai teknik pengawetan tubuh menggunakan pendingin nitrogen cair hingga menjadi beku (kriopservasi/cryopservation). Cryonics diciptakan dengan harapan bahwa manusia dapat memiliki "kehidupan kedua" setelah dinyatakan mati secara klinis setelah menderita penyakit yang tak tersembuhkan (Budiyanti, 2016). Sifat optimisme alami dari saintis mendorong keyakinan bahwa penyakit-penyakit tersebut suatu saat akan ditemukan. Contohnya seperti strategi program penanggulangan penyakit HIV/AIDS secara global oleh UNAIDS di tahun 2030. Pasien yang sesaat telah dinyatakan meninggal secara klinis dengan penyakit HIV/AIDS dapat menggunakan teknik cryonics untuk dibekukan dan dibangkitkan kembali dimasa depan setelah obat dari penyakit tersebut ditemukan.

Menurut prosedur cryonics yang dikeluarkan yayasan Alcor yaitu: kematian klinis dinyatakan dengan berhentinya fungsi jantung dan pernafasan, namun sebenarnya belum meninggal secara biologis karena sel-sel otak tidak mati selama beberapa menit setelah sirkulasi berhenti. Ahli cryonics memanfaatkan momen tersebut sesegera mungkin dalam meminimalisir kerusakan-kerusakan sel di otak untuk dijaga kesetabilannya (Budiyanti, 2016). Prosedur tersebut dilakukan karena merupakan pelanggaran hukum apabila melakukan teknik cryonics pada pasien yang masih hidup.

Teknik cryonicsdianalogikan dengan tingkah laku katak pohon di Amerika bagian utara yang mematikan sistem di dalam tubuhnya di musim dingin, dimana jantungnya berhenti berdetak dan seluruh tubuhnya membeku hingga musim panas tiba dan kembali pada kehidupannya (Roach, 2007).Percobaan ilmiaholeh para ilmuan dengan mengambil sampel binatang menunjukkan hasil yang positif. Percobaan ilmiah Lovelock pada tahun 1950 yang mampu menghidupkan kembali tikus yang telah diawetkan pada suhu 0 dan $1{ }^{\circ} \mathrm{C}$ menggunakan diathermy microwave(Andjus and Lovelock, 1955). Pada tahun 2006 Sydney Morning Herald memberitakan tentang para dokter AS telah mengembangkan metode hipotermia hingga $10^{\circ} \mathrm{C}$ dengan menggunakan sejenis larutan garam dingin pada aliran darahnya untuk mematikan fungsi tubuh pada waktu 3 jam dengan melakukannya pada babi sebanyak 200 kali dengan tingkat akurasi mencapai $90 \%$.

Berdasarkan percobaan tersebut, terdapat konsep ilmiah yang muncul oleh ilmuan cryonics. untuk praktik cryonics yang didasarkan pada beberapa konsep kunci yaitu: 1) suhu rendah dapat memperlambat metabolism, dimana suhu yang cukup rendah bisa menghentikan perubahan kimia selama berabad-abad; 2) pembentukan es pada jaringan tubuh dapat direduksi atau dihilangkan dengan menggunakan campuran vitrification; 3) secara legal kematian tidak termasuk "kematian irreversible", kematian sebagai proses dan memerlukan waktu lama untuk meyakini proses tersebut; 4) kematian klinis yang tidak reversible hari ini, namun secara teoritis dapat reversible di masa depan (Best, 2008).

Cryonis diibaratkan sebagai bagian dari teknik pengobatan modern di masa depan. Ahli nanoteknologi Eric Drexler memandang bahwa cryonics merupakan solusi praktis bagi siapapun yang berharap dan percaya terhadap mukjizat masa depan yang disediakan oleh mesin molekuler (Lafontaine, 2009). Nilai teoricryonics dari kehidupan masa depan akan menjanjikan prospek kehidupan abadi. Penyakit tidak akan menjadi suatu kekhawatiran bagi umat manusia. Makna kematian pun akan berubah tidak lagi sebagai proses dari akhir 
kehidupan, namun merupakan solusi terhadap permasalahan-permasalahan manusia di masa depan.

\section{Tinjauan Aksiologis Teknik Cryonics}

Aksiologi sebagai bagian dari cabang filsafat ilmu yang membahas teori penggunaan ilmu pengetahuan. Aksiologi mencakup nilai dan penilaian dari suatu objek yang berhubungan dengan etika dan estetika. Etika membicarakan perilaku manusia, sedangkan estetika memandang karya manusia dari sudut yang baik dan buruk (Wiramihardja, 2009). Etika sangat terkait dengan filsafat moral dengan mengkaji prinsip-prinsipnya pada prilaku seseorang (Firman, 2018). Dalam kaitannya dengan sains, etika sains berarti membahas prilaku moral yang terkait dengan hakikat sains sebagai ilmu pengetahuan. Pengetahuan semakin berkembang dengan hadirnya teknologi sebagai suplemennya. Salah satu aplikasi ilmu pengetahuan tersebut yang sangat berkaitan dengan moral adalah teknik cryonics.

Kemunculan teknik cryonics langsung menuai berbagai tanggapan kontroversi baik yang setuju atau yang menolaknya. Bagi yang setuju, teknikcryonics dianggap sebagai respon terhadap sifat manusiawi yang ingin bertahan dan menolak untuk mengalah pada nasib mahkluk hidup. Dianalogikan pada masa kini dan masa lalu tentang proses alamiah saat menulis buku, menciptakan suatu karya seni, dan memiliki keturunan, serta meninggalkan warisan menujukeabadian untuk diingat (Barbaro, 2011). Bagi beberapa para penganut ateis beranggapan bahwa teknik ini merupakan surga untuk hidup abadi, selain itu pada contoh ekstrim dapat berupa seseorang yang ingin mengetahui bagaimana kehidupan masa depan seperti melakukan time travel (Shaw, 2011), atau teknik ini juga digunakan untuk migrasi planet dan galaksi menuju tempat hidup yang baru karena pengaruh ledakan penduduk. Contoh tersebut dapat dipandang sebagai suatu yang pragmatis dalam memilih teknik cryonics.Terlepas dari itu,cryonics merupakan suatu cara dalam menghilangkan batasanbatasan manusia dalam kehidupan.

Menghilangkan batasan-batasan manusia dengan teknik cryonics sesungguhnya justru memudarkan makna dari kehidupan itu sendiri dan menggeser makna kematian secara tradisional.Pertanyaan tentang makna kehidupan secara filsafat dan spiritual seperti "apa yang harus dilakukan dalam kehidupan?", "mengapa harus hidup di dunia?", "apa yang harus diraih dalam kehidupan?", "apakah inti kehidupan?" dan masih banyak lagi pertanyaan muncul sebagai proses berpikir manusia berujung pada nilai, tujuan, etika, dan moral terkait kehidupan. Tentu pertanyaan-pertanyaan tersebut tidak dapat dijawab secara serempak dan seragam. Timbul anggapan bahwa kemajuan teknologi telah mengikis logika moral yang melekat pada manusia dalam memperbaiki kehidupan (Pandhi, 2015). Jika dikaitkan dengan agama dan keberadaan Tuhan timbul jawaban tradisional dalam menanggapi cryonics yang dapat diberikan yaitu: pertama, rencana-Nya terhadap keberadaan dunia yang hanya dapat diwujudkan manusia apabila mampu bertindak berdasarkan kehendak Tuhan dan kitab sucinya. Kedua, dunia merupakan ekspresi dari keagungan Tuhan terhadap dosa manusia yang memerlukan pengampunan sebagai bagian-Nya. Ketiga, kehidupan saat ini merupakan persiapan kehidupan setelah kematian di surga atau neraka (Britton, 2017).

Bagi kaum spiritual, makna kehidupan jika dipandang demikian tidak relevan dengan teknik cryonics. Apabila dikaji melalui agama Hindu, berkeyakinan bahwa seseorang yang hidup merupakan bagian dari percikan-percikan suci Tuhan yang merupakan atma atau atman dan masuk ke tubuh makhluk hidup sebagai jiwatmanatau roh. Setelah terjadi kematian klinis maka atman meninggalkan tubuh seseorang, dan atman tersebut hidup kembali berdasarkan karmanya yang dinamakan punarbhawa. Kondisi atman yang demikian berlangsung secara kontinu hingga karma mencapai kesempurnaan dan bersatu dengan Ida Sang Hyang Widhi sesuai tujuan untuk mencapai moksa (bebas dari penjelmaan kembali)(Nirawana, 2015). Hal ini sesuai dengan penjelasan kitab Swetaswatara V.12 yang dijelaskan oleh Persatuan Hindu Dharma Indonesia (www.phdi.or.id)

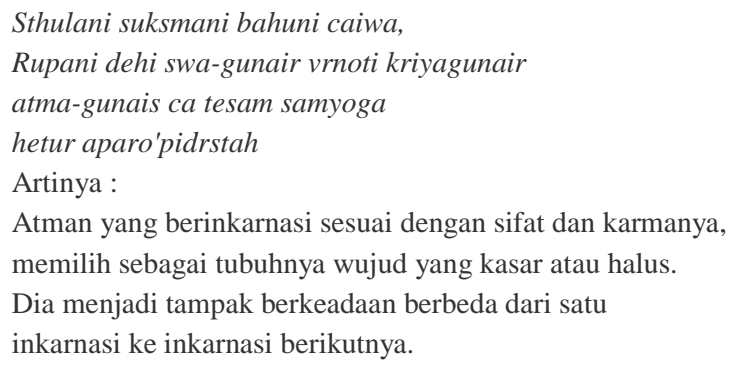


Kajian Hindu tentang kelahiran dan kematian berdasarkan atman tidak bersesuaian dengan teknik cryonics yang berorientasi keabadian. Ketika kematian klinis terjadi atman telah meninggalkan tubuh seseorang untuk dipertimbangkan karmanya berstatus inkarnasi (punarbhawa) pada tubuh yang lain atau telah sempurna mencapai moksa. Bertentangan dengan teknik cryonics yang memulai prosesnya beberapa menit setelah kematian klinis terjadi untuk dibangkitkan kembali di masa depan.Disamping itu, keyakinan bahwa yang dapat hidup abadi hanyalah Tuhan. Dalam agama Hindu, para dewa diinterpretasikan memiliki tubuh seperti manusia, dan yang membedakannya salah satunya yaitu keabadian, namun manusia dengan teknik cryonics di kemudian hari setelah teknologi mencukupi dapat menyetarakan salah satu kemampuan Dewa untuk keabadian (imortalitas). Hal ini menyebabkan hilangnya keyakinan agama melalui revolusi ilmiah, contohnya orang eropa lebih mementingkan suatu kehidupan teknokratis yang mengedepankan sains dan humanisme sebagai rasionalisasi untuk memperoleh keselamatan dibandingkan keyakinan terhadap agama (Turnbull, 2005).Keyakinan terhadap Tuhan sebagai pencipta manusia pun menjadi ancaman keraguan umat di masa depan.

Pada kasus lainnya penggunaan teknik cryonics pada bagian kepala/otak saja (neuropreservation) telah mendorong ilmuwan untuk menciptakan tubuh manusia tanpa kelahiran, namun melalui ciptaan manusia layaknya kloning. Kloning pada manusia hingga saat ini masih menjadi isu yang kontroversial, terutama ketika digabungkan dengan cryonics dan nanoteknologi. Selain itu, pada neuropreservation, para ahli terdorong untuk melakukan mind upload dengan sistem menyalin dan memindahkan isi pikiran manusia ke dalam perangkat teknologi. Di Rusia, beberapa kelompok dikabarkan telah ikut mempromosikan perpanjangan kehidupan melalui teknik cryonics ini untuk mencapai keabadian dengan melakukan "mind uploading" atau "mind transfer," dengan hipotesis kemungkinan memisahkan pikiran dari otak biologis dan menyalinnya ke "platform nonbiologis" (Bernstein, 2015). Cara ini dilakukan tidak lain untuk imortalitas dan dikemudian hari akan menempati suatu tubuh mesin atau tubuh ciptaan manusia dengan mobilitas tak lebih dari proses transfer data dengan sistem jaringan di dalam tubuh untuk melakukan berbagai aktivitas namun tanpa kesadaran dan berwujud virtualisasi atas kematian (Damm, 2011). Pikiran yang telah di-upload atau di-transfer sebagai proses virtualisasi ini semakin memperjelas makna keabadian itu ketika berupa sekumpulan data yang dapat diterapkan pada berbagai tubuh nantinya.Terjadilah pergeseran makna realitas, kehidupan, dan kematian apabila teknologi tersebut telah terwujud.

Teknik cryonics berpotensi menimbulkan aksi bunuh diri (suicide). Keinginan bunuh diri biasanya muncul karena kondisi tertentu yang dialami seseorang yang putus asa. Suatu pasien yang memiliki penyakit tak tersembuhkan dan tak tertahankan menyebabkan aksi bunuh diri menjadi pilihan (Budiyanti, 2016). Kondisi pasien ini dinamakan euthanasia, dengan keyakinan dan keinginankeadaan yang lebih baik di masa depan dengan kemajuan teknologi medis. Pada kasus lainnya, ketika seseorang berada dalam suatu masalah dengan orang lain yang tak terselesaikan, bunuh diri dan hidup kembali di masa depan merupakan suatu pilihan pelarian. Harapan baru muncul pada dunia baru karena masalah telah hilang bersamaan dengan kemungkinan meninggalnya orang lain tersebut. Contoh nyata yang paling kontroversi yaitu oleh Dr. Thomas Donaldson yang melakukan aksi bunuh diri ketika difonis mengalami tumor otak (LaBouff, 1992). la mengakhiri hidupnya bukan karena penderitaan mental atau depresi, namun berdasar pada keyakinan bahwa cryonics kan memberikan kesempatan untuk hidup kembali di masa depan tanpa tumor, sehingga ia mengakhiri hidupnya sebelum penyakitnya menggerogoti bagian otaknya. Selanjutnya ia bergantung kepada yayasan Alcor untuk membantu proses kriopservasi sesegera mungkin setelah detak jantungnya berhenti. Berpijak dari kasus Dr Donaldson tersebut, banyak cryonicists akan mendukung gagasan-gagasan untuk legalisasi euthanasia karena hak privasi dalam mempertahankan hidup pada kasus-kasus tertentu untuk menyelamatkan pasien dari kematian (LaBouff, 1992). Contoh ekstrim ini kemungkinan dapat mendorong orang yang sehat tanpa penyakit pun untuk bunuh diri demi kepentingan kehidupan masa depan namun sesungguhnya hal tersebut hingga saat ini masih terlarang di Indonesia karena keterikatan hukum dan keyakinan.

Agama dan Hukum di Indonesia melarang bunuh diri untuk alasan apapun. Dari sisi agama mempercayai bahwa tuhan merupakan sumber kehidupan. Hanya Tuhan yang berhak untuk memutuskan waktu manusia untuk meninggal. Konsekwensi yang muncul dari kitab Yayur Weda 40.3 yang menyebutkan bahwa: 


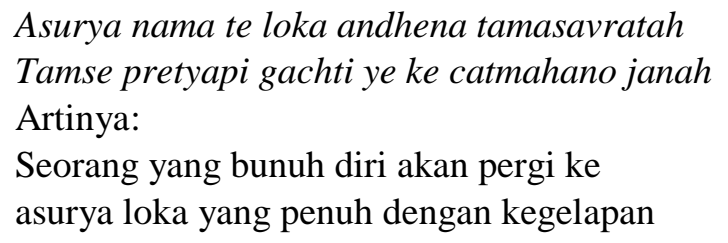

Hukum di Indonesia juga mengatur terhadap siapa saja yang memberikan bantuan atau dorongan untuk melakukan bunuh diri. Pasal 344 dan 345 KUHP mengaturnya dengan memberikan ancaman hukuman pidana penjara. Pandangan dalam bunuh diri disampaikan Damm (2011) yang menyebutkan bahwa bunuh diri dipandang sebagai perwujudan dari suatu ekspresi untuk mengatasi situasi tertentu yang dinilai tidak berubah dan tidak menguntungkan. Namun pada kasus lain, Hume menjelaskan bahwa euthanasiamerupakan suatu tindakan yang tidak menyalahi aturan dan bersifat otonom, karena Tuhan memberikan anugrah untuk melakukannya menuju kehidupan yang lebih baik pada kasus untuk menghilangkan rasa sakit dan penderitaan yang dialami (Damm, 2011).Bagi yang menolak untuk cryonics mengatakan bahwa mengubah legalitas sistem hukum terkait dengan bunuh diri dan euthanasia akan menyebabkan suatu kekhawatiran dimana orang-orang yang tidak benar-benar ingin mati dipaksa untuk melakukan cryonics (Cron, 2014). Apapun alasannya, tindakan bunuh diri hingga saat ini bagi sebagaian orang masih dianggapsuatu tindakan pelarian dan tidak menghargai makna perjuangan.Walaupun semua hal tersebut merupakan pilihan pribadi seseorang, jalan tengahnya mungkin cryonics diperbolehkan, tapi bertentangan dengan etika dan estetika yang berlaku di Indonesia.

Pasien cryonics diprediksi akan memiliki masalah terkait norma sosial dimasa kini dan masa depan. Tidak akan ada gunanya untuk dihidupkan kembali dalam beberapa ratus tahun kemudian setelah diawetkan karena keluarga yang dimiliki saat ini mungkin telah meninggal dan justru mengarah pada kesepian (Shaw, 2011). Disamping itu tidak ada jaminan bahwa kehidupan masa depan akan lebih baik, sebagai seseorang yang mungkin bangkit di masa depan dapat tidak cocok dalam kehidupan masyarakat masa depan. Selain itu, masyarakat masa depan akan sangat berbeda, sehingga akan mengalami pergeseran identitas, dimana kehidupan tidak lagi layak untuk dijalani (Cron, 2014). Kemampuan adaptasi sangat diperlukan pada kasus tersebut. Apabila tidak mampu untuk beradaptasi kemungkinan akan menyebabkan kesendirian dan cryonics hanyalah tindakan sia-sia.

Berbagai ancaman pun patut untuk diperhitungkan di masa depan. Ancaman berupa reaksi masyarakat masa depan terhadap pendatang dari cryonics layak untuk dipertimbangkan. Ancaman terlupakan oleh generasi penerus dapat terjadi karena proses kebangkitan berlangsung dari puluhan hingga ratusan tahun. Krisis identitas yakni keterasingan dari teman dan keluarga yang dicintai merupakan salah satu derita yang dimiliki pasien cryonics di masa depan, terkecuali dengan mengajak beberapa keluarga yang meninggal nanti untuk mengikuti cryonics. Namun hal tersebut tentunya membutuhkan sumber daya terutama pembiayaan yang tidak sedikit.

Teknik cryonics memerlukan proses penyimpanan dengan waktu yang lama. Biaya yang tentu tidak akan murah untuk menjaga suhu tubuh atau hanya bagian kepala saja secara konstan mendekati 0 mutlak selama itu. Hal ini menyebabkan hanya kaum golongan atas saja yang bisa menjangkau cryonics dan mengabaikan asas pemerataan. Beberapa perusahaan cyonic pun menetapkan sejumlah biaya awal untuk persiapan, diluar biaya perawatan dan biaya tahunan untuk penyimpanan, serta biaya yang belum diprediksi untuk proses membangunkan pasien dari kematiannya nanti; tentunya diluar biaya rumah sakit sebelum proses cryonics terjadi (Shaw, 2011). Tim cryonics pun harus siap siaga menunggu proses kematian terjadi karena harus dibekukan secepat mungkin, dan itu juga memerlukan biaya. Untuk mengatasinya, kini beberapa perusahaan telah menyarankan untuk mendaftarkan di asuransi cryonics. Salah satu contoh pembiayaan cryopservationoleh yayasan Alcor untuk seluruh tubuh adalah $\$ 200.000,00$ dan $\$ 80.000,00$ untuk neuropreservation, dengan kriteria diluar biayabiaya tambahan seperti di luar Amerika Serikat, negara tertentu, dan non anggota pada kisaran $\$ 10.000,00$ hingga $\$ 50.000,00$ (www.alcor.org). Bagi keluarga yang berkecukupan hal ini tentu tidak jadi masalah, namun bagi yang memiliki pendapatan terbatas untuk mendapatkan cryonics adalah memprihatinkan. Sekalipun mampu membayarnya, ketika dihidupkan di masa depan tentu kondisi finansial sudah sangat berbeda, karena nilai uang saat ini sangat kecil dibandingkan masa depan. Cryonics pun dianggap sebagai suatu investasi yang membuang uang (Shaw, 2011). 
Sumber daya alam yang digunakan untuk cryonics berupa gas nitrogen cair tentu sangat banyak. Penghabisan sumber daya alam untuk seorang yang di cryonics tentu lebih banyak dibandingkan kremasi atau pemakaman. Ketika cryonics menjadi suatu keberhasilan, maka akan merespon banyak orang untuk bergabung. Pada akhirnya sumber daya alam yang digunakan akan semakin banyak dan keseimbangan alam semesta terganggu.

Ajaran agama Hindu memiliki pandangan keharmonisan dan kebahagiaan, serta keserasian yang disebut tri hita karana. Tri artinya tiga, hita artinya kebahagiaan, dan karana artinya penyebab. Falsafah Tri hita karana meliputi hubungan yang harmonis antara manusia dengan Tuhan, sesama manusia, dan manusia dengan lingkungan hidupnya yang saling terintegrasi. Wujud bhakti manusia dengan Tuhan dilakukan dengan cara beribadah dan melaksanakan setiap ajaranNya karena keyakinan bahwa Tuhan lah sumber dari segala sumber kehidupan. Hubungan harmonis sesama manusia dilakukan dengan menghargai, mengasihi, dan membimbing untuk menciptakan kebahagiaan lahir batin dalam besosialisasi. Hubungan manusia dengan lingkungan meyakini bahwa segala kebutuhan hidup disediakan oleh lingkungan, sehingga lingkungan patut dijaga keseimbangan dan kelestariannya. Terkait dengan cryonics, memang ajaran tri hita karana kontradiktif terhadap permasalahanpermasalahan yang ditimbulkan di masa depan. Kehidupan seolah menjadi aturan manusia, kehidupan sesama manusia masa depan yang beresiko, dan dampak lingkungan yang ditimbulkan dari cryonics. Bagaimanapun, tentu peran ilmu pengetahuan dan teknologi bersifat netral, dan yang mempermasalahkan kebermanfaatannya atau kerugiannya adalah manusia sebagai pembuat keputusan termasuk saintis, teknokrat, politikus, pengusaha, dan penggunanya (Firman, 2018).

\section{Kesiapan Hukum di Indonesia tentang Cryonics}

Kajian terhadap hukum di Indonesia dalam mengatur pelaksanaan cryonics perlu dilakukan. Hal ini bukan semata-mata telah menyetujui cryonics secara langsung, namun merupakan bentuk antisipasi agar tidak bertentangan dengan norma-norma yang berlaku di masyarakat Indonesia terutama karena keyakinan beragamanya. Tentang kematian diatur dalam Pasal 117 UU. No. 36 Tahun 2009 tentang kesehatan yang menyebutkan bahwa "Seseorang dinyatakan mati apabila fungsi system jantung-sirkulasi dan system pernapasan terbukti telah berhenti secara permanen, atau apabila kematian batang otak telah dibuktikan". Tidak hanya itu, pemberian keterangan dalam penanganan kematian terkait sertifikasi yang menghasilkan surat keterangan meninggal hendaknya perlu dikaji, mengingat pasien cryonics diprediksi akan kebangkitan dimasa depan. Pada kasus euthanasia hukum juga harus mengatur bagaimana bunuh diri yang dibantu dapat berujung pada proses autopsydengan melakukan pembedahan. Hal ini sulit dilakukan karena cryonics memerlukan waktu yang sesegera mungkin untuk diproses setelah dinyatakan meninggal secara klinis dan menjaganya pada suhu konstan. Proses ini bertentangan dengan pasal 222 KUHP ketika dengan sengaja menghalang-halangi pemeriksaan mayat cryonics. Peraturan sangat diperlukan untuk ditetapkan agar perkembangan teknologi cryonics tidak menimbulkan dilema etika dan berbagaimasalah hukum (Budiyanti, 2016).

\section{Simpulan}

Cryonics sebagai produk ilmu pengetahuan dan teknologi menyediakan suatu pilihan bagi masyarakat khususnya untuk memperoleh perpanjangan hidup dari derita penyakit yang belum tersembuhkan saat ini. Keberatan etika dan estetika pun muncul dalam menanggapi cryonics karena bertentangan dengan nilai agama, norma, dan nilai sosial yang berlaku di masyarakat. Bagi yang setuju beranggapan bahwa Cryonics muncul karena keinginan alami manusia untuk mengatasi keterbatasan yang dimiliki hingga kemungkinan menuju keabadian ketika berhasil sepenuhnya. Walaupun demikian, cryonics menimbulkan dilema dalam aplikasinya karena berpotensi meningkatkan kasus bunuh diri dan euthanasia. Pada Neuropreservation berpotensi untuk dilakukan kloning ataupun mind-upload pada manusia untuk mengaktifkannya dan tentu hingga saat ini masih dilarang.Cryonics juga berpotensi merubah makna kematian baik dari segi klinis maupun hukum di Indonesia. Kesiapan di Indonesia dari segi hukum perlu dikaji ulang. Sosialisasi dan diskusi dini terkait etika dalam pemanfaatan teknik cryonics sangat diperlukan sebelum memasuki wilayah Indonesia. 


\section{Daftar Pustaka}

Andjus, R. K. \& Lovelock, J. E. (1955). Reanimation of rats from body tempreaturesbetween 0 and $\mathrm{I}^{\circ} \mathrm{C}$ by microwave diathermy.J. Physiol (1955). I(28). 541-546.

Barbaro, V. (2011). Heaven for Atheis. The Humanist. 71(4). 24-29.

Bernstein, A. (2015). Freeze, die, come to life: The many paths to immortality in post-Soviet Russia.American Ethnologist. 42(4). 766-781.Best,

B. P. (2008). Scientific Justification of Cryonics Practice. Rejuvenation Research. 11(2). 493503.Briton, K. (2017). Philosophy and The Meaning of Life Filsafat sebagai Lentera Kehidupan Edisi Terjemahan. Jogjakarta: Ar-Ruzz Media.

Budiyanti, R. T. (2016). Teknologi Cryonics dalam Perspektif Etika dan Hukum. 43(8). 626-629.

Cron, R. (2014). "Is Cryonics an Ethical Means of Life Extension?". University of Exeter. 1-29.

Damm, M. (2011). Kematian Sebuah Risalah tentang Eksistensi dan Ketiadaan. Depok: Kepik.

Firman, H. 2018. FilsafatSains. Program studi Pendidikan Ilmu Pengetahuan Alam, Sekolah Pascasarjana, Universitas Pendidikan Indonesia. Tidak diterbitkan.

LaBouff, J. P. (1992). "He wants to do what?" Cryonics: issues in questionable medicine and self-determination. Santa Clara computer and hightechnology law journal. 8(2). 469498.

Lafontaine, C. (2009). The Postmortal Condition: From the Biomedical Deconstruction of Death to the Extension of Longevity. Science as Culture. 18(3). 297-312.

Lohmeier, J. et al. (2015). Social profile and attitudes of cryonics advocates and deniers in Germany: a representative study. Mortality. 20(3). 263-279.

Moen, O. M. (2015). The case for cryonics. Journal of Medical Ethics. 41(8). 677-681. Nirawana, H. A. (2015).

Nirwana dan Cara Pencapaiannya dalam Agama Hindu. Jurnal Al-Adyaan. I(2). 99-103.

Oxford, E. N. (2003). Oxford Dictionary of Physics. Oxford Uni. Oxford: Oxford University Press.

Pandhi, A. (2015). Chilling legalities of cryopreservation. International Journal of Sosio-Legal Analysis and Rural Development. 3(II). 96-105.

Roach, J. 2007. Antifreeze-Like Blood Lets Frog Freeze and Thaw with Winter's Whims. (https://news.nationalgeographic.com/news/2007/02/070220-frog-antifreeze.html).

Sydney Morning Herald. 2006. Doctors claim suspended animation success. (https://www.smh.com.au/news/health-and-fitness/doctors-claim-suspendedanimation-success/2006/01/20/1137553739997.html).

Shaw, D. M. (2009). Cryoethics: seeking life after death. Bioethics. 23 (9).515-521.

Thomson, H. (2016). The big freeze. New Scientist. 231(3080), 26-31.

Wiramihardja, S. A. 2009. Pengantar Filsafat: Sistematika dan Sejarah Filsafat, Logika dan Filsafat IImu (Epistemologi), Metafisika dan Filsafat Manusia, Aksiologi. Bandung: PT. Refika Aditama. 